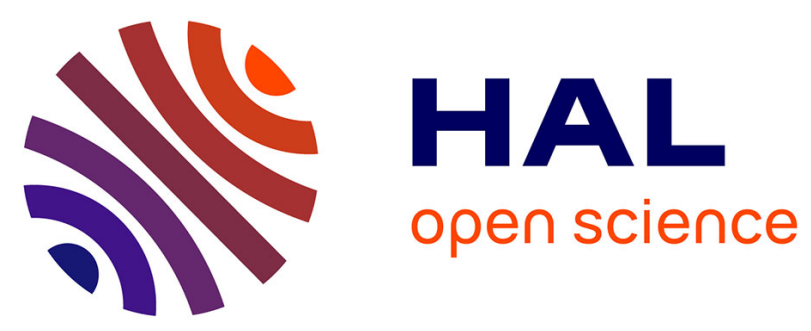

\title{
The Catchment Water-Based System Health Evaluation Based on the TOPSIS Model
}

\author{
Zhenxiang Xing, Jing Li, Meixin Liu, Qiang Fu, Hao Guo
}

\section{To cite this version:}

Zhenxiang Xing, Jing Li, Meixin Liu, Qiang Fu, Hao Guo. The Catchment Water-Based System Health Evaluation Based on the TOPSIS Model. 8th International Conference on Computer and Computing Technologies in Agriculture (CCTA), Sep 2014, Beijing, China. pp.233-239, 10.1007/9783-319-19620-6_29. hal-01420237

\section{HAL Id: hal-01420237 https://hal.inria.fr/hal-01420237}

Submitted on 20 Dec 2016

HAL is a multi-disciplinary open access archive for the deposit and dissemination of scientific research documents, whether they are published or not. The documents may come from teaching and research institutions in France or abroad, or from public or private research centers.
L'archive ouverte pluridisciplinaire HAL, est destinée au dépôt et à la diffusion de documents scientifiques de niveau recherche, publiés ou non, émanant des établissements d'enseignement et de recherche français ou étrangers, des laboratoires publics ou privés. 


\title{
The Catchment water-based system Health
}

\section{evaluation based on the TOPSIS model}

\author{
Zhenxiang Xing ${ }^{1,2,3, \mathrm{a}}$, Jing $\mathrm{Li}^{1, \mathrm{~b}}$ Meixin Liu ${ }^{1, \mathrm{c}}$, Qiang $\mathrm{Fu}^{1,2,3, \mathrm{~d}}$, Hao Guo ${ }^{1, \mathrm{e}}$, \\ ${ }^{1}$ College of Water Conservancy \&Civil Engineering, Northeast Agricultural University, \\ Harbin 150030, China; ${ }^{2}$ Collaborative Innovation Center of Grain Production Capacity \\ Improvement in Heilongjiang Province, Harbin 150030, China; ${ }^{3}$ The Key lab of Agricultural \\ Water resources higher-efficient utilization of Ministry of Agriculture of PRC, Harbin \\ 150030,China; \\ axxneau@hotmail.com, ${ }^{\mathrm{b}}$ lijingneau@sina.com, ${ }^{\mathrm{c}}$ liumeixinneau@sina.com, \\ dfuqiangneau@sina.cn, ${ }^{\mathrm{e}}$ ghneau@sina.cn
}

\begin{abstract}
The health status of Naolihe Basin has already varied significantly affected by the climate change and human activity. Therefore, it is reasonably much important to analyze and evaluate the health status of river, which could provide basis for the comprehensive development and protection in the Naolihe Basin. So, this paper takes Baoqing country as the study region, uses the stable state, the harmonious degree and evolution rate to describe the health status, and establishes the health evaluation index system of water-based system in Baoqing country based on the concept of water-based system. The entropy method is used to the weight vector of steady state index and harmonious degree index, the TOPSIS was applied to analysis the health status of water-based system of Baoqing country during 2005 to 2009. The comprehensive evaluation result shows that the water-based system of Baoqing country is in the state of comparative healthy, the main reason is that water resources of the study area are relatively insufficient, and drinking water security and water consumption cannot obtain the complete guarantee, which leads to lower steady state.
\end{abstract}

Keywords: Naolihe Basin; water-based system; health assessment; entropy weight method; TOPSIS 


\section{Introduction}

Water-based system refers to habitats carrying system that is made up of water and related wading medium and engineering in a certain hydrological scale and spatial dimensions. Space for different hydrological scale, water-based system has different characteristics. The system covers the water, air, soil, biological, social economy and many other aspects, which is a comprehensive on river health, the development and utilization of drainage basin water resources and regional water resources carrying capacity, etc. It is a huge system on real significance [1-2].

At present, the study of water-based system is still in its primary stage, with few related research and application. Zhou Huicheng etc. [3-4] put forward the concept of city water system, which established water system health index of Dalian city. Xiang Biwei etc. [5] established the water-based system of Dongiiang River Basin and constructed the index system of ecosystem health assessment of the Dongjiang River Basin Water System based on the water-based system. The rough set theory and set pair analysis were applied to the water-based system in Dongiiang River Health Assessment by Huang Guoru etc [6].

BaoQing is located in the northeast of Heilongjiang province, belongs to Shangyashan city. BaoQing's economy keeps developing fast and rich in resources [7]. It is an important commodity grain base. However, economic development have done much harm to the resource environment and threatened the regional Health.

\section{Regional Health Assessment Index Based on Water-Based Systems}

To consider the influence of the consistency of the system variables, contradictory, and time variability on the system, we need to describe the characteristics of the system in water base system. When we evaluated the health status of water-based systems, we used the three characteristic properties of water-based systems to characterize the state of water-based systems, namely stability, harmony and evolutionary. Meanwhile we used the stable state, the harmonious degree and evolution rate to describe. Because the economy of studied areas was dominated by agriculture, we put forward table 1 and 2 through the study of theories related and the combination of natural and social characteristics of the study area. Table 1 represents the index and standard value of steady state and 2 represents the index and standard 
value of harmonious degree. The evolution rate represents the degree of change of water-based systems on the time scale to track and characterize the stability and harmony of water-based system. So evolution rate can be divided into steady state evolution rate and the harmonious degree evolution rate. By using the calendar feature values of steady-state and harmony to draw the break point diagrams of steady-state and harmony, we select the slope of the process line as a characteristic value of evolution rate. Index and standard value of evaluation rate are shown in table 3 .

Table 1. Index and standard value of steady state

\begin{tabular}{cccccccc}
\hline rank & Un & $\begin{array}{c}\text { Pd/per } \\
\left(\mathrm{km}^{2}\right)^{-1}\end{array}$ & $\begin{array}{c}\text { Pswla/ } \\
(\%)\end{array}$ & Pcse/ $(\%)$ & $\begin{array}{c}\mathrm{Cf} \\
\mathrm{kg} \cdot\left(\mathrm{km}^{2}\right)^{-1}\end{array}$ & $\begin{array}{c}\mathrm{Cp} / \mathrm{t} \cdot \\
\left(\mathrm{km}^{2}\right)^{-1}\end{array}$ & $\begin{array}{c}\mathrm{Ga} \\
/ \mathrm{m}^{2}\end{array}$ \\
\hline I & $<40$ & $<30$ & $<5$ & $>90$ & $<100$ & $<0.5$ & $>20$ \\
II & $40 \sim 50$ & $30 \sim 60$ & $5 \sim 10$ & $80 \sim 90$ & $100 \sim 150$ & $0.5 \sim 2$ & $11 \sim 20$ \\
III & $50 \sim 60$ & $60 \sim 70$ & $10 \sim 15$ & $70 \sim 80$ & $150 \sim 225$ & $2 \sim 3$ & $6 \sim 11$ \\
IV & $>60$ & $>70$ & $>15$ & $<70$ & $>225$ & $>3$ & $<6$ \\
\hline
\end{tabular}

Note:a, I IV level respectively: very stable, stable, basically stable and unstable; Un: urbanization progress; Pd: population density (per $\left.\left(\mathrm{km}^{2}\right)^{-1}\right)$; Pswla: proportion of soil and water loss area (\%);

Pcse: proportion of controlling soil erosion (\%);

$\mathrm{Cf}$ : consumption of fertilizer; $\mathrm{Cp}$ : consumption of pesticides; Ga: green area.

Table 2. Index and standard value of harmonious degree

\begin{tabular}{|c|c|c|c|c|c|c|c|c|}
\hline rank & $\begin{array}{c}\text { Lwcpc /L } \\
\cdot(\text { per } \\
\text { d) } \\
)^{-1}\end{array}$ & $\begin{array}{c}\text { Rufiw } \\
\qquad \%\end{array}$ & Iwd $/ \%$ & $\begin{array}{c}\text { Hwccpp } \\
\text { /\% }\end{array}$ & Pwa $/ \%$ & $\begin{array}{c}\text { Prdws } \\
\qquad / \%\end{array}$ & $\mathrm{Pw} / \%$ & Peia $/ \%$ \\
\hline I & $>300$ & $>60$ & $>90$ & $<30$ & $>10$ & $>90$ & $>50$ & $>90$ \\
\hline II & $200 \sim 300$ & $50 \sim 60$ & $80 \sim 90$ & $30 \sim 40$ & $5 \sim 10$ & $80 \sim 90$ & $50 \sim 30$ & $80 \sim 90$ \\
\hline III & $150 \sim 200$ & $40 \sim 50$ & $70 \sim 80$ & $40 \sim 50$ & $3 \sim 5$ & $70 \sim 80$ & $20 \sim 30$ & $60 \sim 80$ \\
\hline IV & $<150$ & $<40$ & $<70$ & $>50$ & $<3$ & $<70$ & $<20$ & $<60$ \\
\hline
\end{tabular}

Note: I IV level respectively: very harmonious, harmonious, basic harmonious and disharmony; Lwcpc: life water consumption per capita; Rufiw: repeating utilization factor of industrial water; Hwccpp: high water consumption crop planting proportion; Iwd: industrial water disposal; Pwa: proportion of water area; Prdws: proportion of rural drinking water standards; 
Table 3. Index and standard value of evaluation rate

\begin{tabular}{ccc}
\hline rank & steady state evolution rate & $\begin{array}{c}\text { harmonious degree } \\
\text { evolution rate }\end{array}$ \\
\hline I & $<-0.02$ & $<-0.02$ \\
II & $-0.02 \sim 0$ & $-0.02 \sim 0$ \\
III & $0 \sim 0.2$ & $0 \sim 0.2$ \\
IV & $>0.2$ & $>0.2$ \\
\hline
\end{tabular}

\section{Comprehensive Evaluation of the Health of Water-Based Systems}

TOPSIS model is a method for multi-objective-decision-making, also known as approaching ideal solution [8 11]. According to nature of the index itself and index data, two contrast regimens are calculated, namely virtual positive ideal solution and virtual negative ideal solution. The formula as follows:

$$
\begin{aligned}
& \mathrm{Z}^{*}=\left\{\left(\max Z_{i j} / j \in J\right),\left(\min Z_{i j} / i \in J^{\prime}\right) \quad i=1,2, \ldots, n\right\}=\left\{Z_{1}^{*}, Z_{2}^{*}, \ldots, Z_{n}^{*}\right\} \\
& \mathrm{Z}^{-}=\left\{\left(\max Z_{i j} / j \in J\right),\left(\min Z_{i j} / i \in J^{\prime}\right) \quad i=1,2, \ldots, n\right\}=\left\{Z_{1}^{-}, Z_{2}^{-}, \ldots, Z_{n}^{-}\right\}
\end{aligned}
$$

where: $Z_{i j}$ is the element of the standardized weighted matrix, $J 、 J$ ' stand for index of the bigger the optimal type and index of the smaller the optimal type.

Calculate positive ideal reference solution $S_{i}^{+}$and negative ideal reference solution $S_{i}^{-}$ of each monitoring site by using the Euclidean distance coefficient.

$$
\begin{aligned}
& \mathrm{S}_{i}{ }^{+}=\sqrt{\sum_{i=1}^{n}\left(Z_{i j}-Z_{j}^{*}\right)^{2}}(i=1,2, \ldots, n) \\
& \mathrm{S}_{i}^{-}=\sqrt{\sum_{i=1}^{n}\left(Z_{i j}-Z_{j}^{-}\right)^{2}}(i=1,2, \ldots, n)
\end{aligned}
$$

Once the distance from each monitoring site was determined, the relative closeness coefficient $C_{i}^{*}$ of each monitoring site can be computed by equation (5)

$$
C_{i}^{*}=S_{i}^{-} /\left(S_{i}^{*}+S_{i}^{-}\right), 0 \leq C_{i}^{*} \leq 1 \quad(i=1,2, \ldots, n)
$$

If an index value of the monitoring site is same with the positive ideal reference solution, then $C_{i}^{*}=1$; If an index value of the monitoring sites is same with the negative ideal reference solution, then $C_{i}{ }^{*}=0$. 
TOPSIS method was used for water-based system health evaluation. First of all, we confirm the characteristic values of stable state and the harmonious degree of water-based systems. Then we obtain the evolution rate by the characteristic values. In the end, the stable state, the harmonious degree and evolution rate are assessed comprehensively.

\subsection{Determine the Index Weight}

There are currently a lot of methods to confirm index weight in the multi-index comprehensive evaluation, such as the Delphi method and Analytic Hierarchy Process (AHP), Mean square deviation method, Membership frequency method and Principal Component Analysis (PCA) [12]. Entropy method can obtain the weight by mining data own information and eliminate the influence of subjective judgment of the index weight [13-14], and make the index weight results more objective. The index of steady state and index of harmonious degree are calculated by the Entropy method.

$$
\begin{aligned}
& \alpha_{\text {稳 }}=[0.1266,0.1171,0.1059,0.1449,0.1076,0.1303,0.1300,0.1376] \\
& \beta_{\text {和 }}=[0.1218,0.1219,0.0916,0.1218,0.1225,0.1025,0.1025,0.0927,0.1226]
\end{aligned}
$$

\subsection{Steady State and Harmonious Degree Evaluation}

\subsubsection{Determine the characteristic value of steady state rank and harmony} degree rank

We select the standard values to establish matrix in table 1 and 2 . Though the normalized processing and weight vector, weighted normalized matrix is obtained. Finally we calculated the Euclid approach degree of each level, namely, the standard value of steady state rank and harmony degree rank, shown in table 4 .

\subsubsection{Calculate the characteristic value of steady state and harmony degree}

Characteristic matrix is composed of the index value and standard values of steady state and harmony degree of study area. By taking the characteristic matrix to the TOPSIS model, we calculate the approach degree to obtain the characteristic value of steady state and harmony degree in Baoqing during 2005-2009. Then by comparing 
the characteristic value of steady state rank and harmony degree rank, we obtain steady state rank and harmony degree rank, shown in table 5.

Table 4. Grade standards of steady state and harmonious degree

\begin{tabular}{cc|cc}
\hline steady state rank & standard deviation & harmony degree rank & standard deviation \\
\hline I & $>0.66$ & I & $>0.63$ \\
II & $0.48 \sim 0.66$ & II & $0.36 \sim 0.63$ \\
III & $0.24 \sim 0.48$ & III & $0.18 \sim 0.36$ \\
IV & $<0.24$ & IV & $<0.18$ \\
\hline
\end{tabular}

Table 5. Grades of steady state and harmonious degree

\begin{tabular}{lcc|ccc}
\hline years & characteristic value & steady state rank & years & characteristic value & harmony degree rank \\
\hline 2005 & 0.48 & III & 2005 & 0.55 & II \\
2006 & 0.45 & III & 2006 & 0.50 & II \\
2007 & 0.49 & III & 2007 & 0.42 & III \\
2008 & 0.49 & III & 2008 & 0.48 & III \\
2009 & 0.41 & III & 2009 & 0.52 & II \\
\hline
\end{tabular}

\subsection{Assessment of Evolution Rate}

According to the characteristic value of stable state and the harmony degree in table 5 , we calculate the evolution rate of steady state and harmony degree. Combining the table 3, we obtain the evolution rate of water-based systems during 2006-2009, shown in table 6 .

\subsection{Comprehensive Assessment of the Health of Water-Based Systems}

Based on the analyzing the stable state, the harmonious degree and evolution rate respectively, we can a comprehensive evaluation for the health of water-based systems. According to the actual situation of the study area, we assigned the weight of stable state, evolution rate of steady state, harmony degree and evolution rate of harmony degree. Finally, the weight was $0.4,0.4,0.1,0.1$. In addition, due to the smaller numerical of the evolution rate, we cannot directly combine the evolution rate with stable state and harmony degree. Therefore, we need to normalized calculation 
for evolution rate, and then make a comprehensive evaluation. If the value $\geq_{0.62}$, system is in healthy state; If the value $0.42 \sim 0.62$, system is in healthier state. The evaluation results listed in table 7 .

Table 6. Grades of evaluation rate

\begin{tabular}{ccccc}
\hline years & 2006 & 2007 & 2008 & 2009 \\
\hline evolution rate of steady state & -0.01 & 0.03 & -0.003 & -0.08 \\
rank & IV & III & IV & IV \\
evolution rate of harmony degree & -0.05 & 0.08 & 0.05 & 0.04 \\
rank & IV & III & III & III \\
\hline
\end{tabular}

Table 7. Assessment result of Baoqing water-based system

\begin{tabular}{cccccc}
\hline years & 2005 & 2006 & 2007 & 2008 & 2009 \\
\hline characteristic value & 0.514 & 0.472 & 0.466 & 0.558 & 0.462 \\
rank & healthier & healthier & healthier & healthier & healthier \\
\hline
\end{tabular}

\subsection{The Evaluation Results Analysis}

We can see from Table 5, the steady state of Baoqing was in grade III. The main reason lies in the study area less water, leading to safe drinking water and water consumption cannot get effective guarantee. Therefore, when efforts to increase water resources development, it is easy to cause instability of water-based system. The level of harmony degree is superior to the steady state level, in the majority with II level. This is mainly because the study area is mainly dominated by agriculture, while the study about renovation and destruction of water-based systems is relatively less. Comprehensive health state of water-based systems was in a relatively healthy state and has also been picking up in 2007.

\section{Conclusions}

In this paper, a water-based system evaluation model is introduced to catchment health assessment, and the health evaluation index system of water-based system was established according to the actual situation of Baoqing country of Naoli river basin, 
and then the TOPSIS model was used to evaluate catchment health status. Through the study, several conclusions were drawn as follow:

(1)The health status of water-based system of Baoqing country was relatively lower, the main reason was that water resources of the study area are relatively insufficient, and drinking water security and water consumption cannot be guaranteed completely, which lead to the lower steady state.

(2)In order to improve the health status of water-based system of Baoqing country, relies on improving the rate of water resources should be improved, increasing the irrigation area should be developed, and the awareness of savings water should be raised, and so on.

(3)The evaluation index system for Baoqing was not mature completely due to the limitation of data and research methodology, and certain limit of determination of evaluation indexes cause agricultural characteristics of Baoqing. A further research should be considered with more data of industrial and environmental index.

\section{Acknowledgment}

Funds for this research was provided by the national natural science foundation (51109036; 51179032), the specialized research fund for the doctoral program of higher university of the Ministry of Education (20112325120009) the special scientific research funds for Ministry of water resources public welfare industry (201301096), The leader talent echelon back-up headman funding projects of Heilongjiang province (500001), the studying funds of postdoctoral in Heilongjiang province (LBH-Q12147), the science and technology project of Heilongjiang Provincial Education Department(11541022).

\section{References:}

1. Liu Ning. Study on the concept, connotation and evolvement of the base-system of water [J]. Advances in Water Science, 2005, 16 (4):475-481. (in Chinese)

2. Liu Ning, Du Guozhi. Integrating the hydrological technology for analyzing the base-system of water [J]. Advances in Water Science, 2005, 16 (5):696-699. (in Chinese) 
3. Zhou Huicheng, Cong Fangjie. Multi-objective fuzzy assessment of health of Dalian water-based system[J]. Journal of Dalian University of Technology, 2008, 48 (5):720-725. (in Chinese)

4. Zhou Huicheng, Cong Fangjie. Evaluation of Dalian water-based system based on index weight reliability analysis [J]. Journal of Liaoning Technical University (Natural Science), 2008, 27(5):770-773. (in Chinese)

5. Xiang Biwei, Huang Guoru, Feng jie. Fuzzy Comprehensive Assessment of Water-based System Health for Dongjiang Basin Based on AHO Method [J]. Water Resources and Power, 2011, 29 (10):1-4. (in Chinese)

6. Huang Guoru, WU Chuanhao, Xiang Biwei. Health state assessment of water-based system for Dongjiang basin based on rough set theory and set pair analysis [J]. Systems Engineering-Theory \& Practice, 2013, 33(1):1 7. (in Chinese)

7. Kuang Wenhui, Zhang Shuwen, Hou Wei.etc. Baoqing County of Sanjiang Plain Land Use Change TuPu Analysis [J]. Journal of the Graduate School of the Chinese Academy of Sciences, 2006, 23(2):242-250. (in Chinese)

8. Pan Ni, Zhou Shuhua. Improved Entropy Weight-based TOPSIS Model and Its Application [J].Yunnan Water Power, 2007, 23(5): 8 12. (in Chinese)

9. Hu Yonghong. The Improved Method for TOPSIS in Comprehensive Evaluation[J]. Mathematics In Practice and Theory, 2002,32(4):572 575. (in Chinese)

10. Li,Xiaofeng, Liu Zongxin, Peng Qinge. Improved Algorithm of TOPSIS Model and Its Application in River Health Assessment[J]. Journal of Sichuan University(Engineering Science Edition), 2011,43(2):14 20. (in Chinese)

11. Wang T C,Chang T H.Applieation of TOPSIS in evaluating initial training aircraft under a fuzzy environment[J].Expert Systems with Applications,2007,33:870 880.

12. Ma Yan. The fuzzy synthetic evaluation of water resource sustainable development and utilization in Xi' an city based on AHP[D].Xi'an: Chang' an University,2008. (in Chinese)

13. Md Masud Hasan, Peter K Dunn. Entropy, consistency in rainfall distribution and potential water resource availability in Australia[J]. Hydrological processes, 2011,25:2613 2622.

14. Wang Yanfang. Matter-element Model Based on Coefficients of Entropy for Comprehensive Evaluation of Irrigation Water Quality[J]. Journal of Irrigation and Drainage, 2009,28(3):73-76. (in Chinese) 